\title{
Physiological Changes During the Adaptation of Hybridoma Cells to Low Serum and Serum-Free Media
}

\author{
Sadettin. S. Ozturk and Bernhard O. Palsson* \\ Department of Chemical Engineering, University of Michigan, \\ Ann Arbor, Michigan 48109
}

Received January 1, 1990/Accepted May 23, 1990

\begin{abstract}
Two murine hybridoma cell lines (167.4G5.3 and S3H5/ $\gamma 2 \mathrm{bA} 2)$ were adapted to grow in low-serum and serumfree media by a weaning procedure. The changes in cell growth, metabolic, and antibody production rates with adaptation were examined using biochemical and flow cytometric analyses. After adaptation to a particular serum level, the short-term serum response of the cells was experimentally determined. Specific growth rates, glucose and glutamine uptake and lactate and ammonia production rates, and specific antibody production rates were evaluated from the data. For both cell lines, an improvement in cell growth was observed after adaptation, and both higher growth rates and higher cell concentrations were obtained. The specific glucose and glutamine uptake rates and the lactate and ammonia production rates changed insignificantly with adaptation. Conversely, changes in the specific antibody production rate of the two cell lines differed. Cell line 167.4G5.3 showed a loss in antibody productivity at low serum levels, while the $\mathrm{S} 3 \mathrm{H} 5 / \gamma 2 \mathrm{bA} 2$ kept its original productivity in low-serum-containing media. The intracellular antibody content for $\mathrm{S} 3 \mathrm{H} 5 / \gamma 2 \mathrm{bA} 2$ cells remained unaltered by adaptation, but a low antibody containing cell population appeared in the $167.4 \mathrm{G5} .3$ culture. The loss of specific antibody productivity in this cell line was due to the appearance of this population.
\end{abstract}

\section{INTRODUCTION}

Economic cultivation of mammalian cells in vitro in large-scale bioreactors is hampered by stringent growth requirements, shear sensitivity, and low product expression rates and the consequent difficulty in product separation. In most cases, serum or serum substitutes have to be used to support cell growth. However, the use of serum is undesirable because of its high cost and the complications introduced by the serum proteins for separation of products. Accordingly, several serum-free and protein-free media have been developed. These media have been used successfully for the cultivation of a variety of mammalian cells. ${ }^{1,2}$

Cells are conditioned to grow better in low-serum or serum-free media by an adaptation procedure. ${ }^{1,3,4}$

\footnotetext{
* To whom all correspondence should be addressed.
}

When the cells are maintained in low-serum media for a sufficiently long time, they typically acquire higher growth rates. This process is often called "adaptation," indicating the self-adjustment of the cells to the environment. ${ }^{*}$ The number of generations required for adaptation depends on the cell line and on the composition of the media ${ }^{5,6}$ Gradual reduction in serum concentration with time increases the probability of successful adaptation to low-serum or serum-free media. Further, successful cultivation of hybridoma cells in low-serum or in serum-free media can be enhanced by adaptation of myeloma cells to low serum prior to fusion. ${ }^{7}$

At present, the process of adaptation is ill-defined in biochemical terms. However, a number of changes have been observed to take place during adaptation. Improvement in the growth rate is perhaps the most evident change that occurs during adaptation to lowserum-containing media. The improvement in growth rate suggests changes in the cells' response to growthpromoting factors provided by serum. It has been shown, for instance, for human breast cancer cell line MCF-7, that the number of estrogen receptors changes during the adaptation process. ${ }^{8}$ Another change that has been observed to take place during adaptation of hybridoma cells is alteration in the specific antibody productivity of the cells. ${ }^{9}$ Scant information is available on the changes that may take place in cellular metabolism during adaptation.

In this article, the effects of adaptation on cell growth, metabolic, and antibody production rates were studied in detail for two hybridoma cell lines in two different media. The cells were first adapted to grow at different serum concentrations (adaptation serum level). Then the adapted cells were grown for a short period of time in different serum concentrations (short-term serum level), and the changes resulting from adaptation were examined. Cell growth, metabolism, and antibody

\footnotetext{
* The use of the term adaptation does not distinguish between actual physiological changes and the selection of a subclone, or mutant cells.
} 
production kinetics were the parameters studied. The effect of adaptation on intracellular DNA and antibody content was investigated by flow cytometric analyses.

\section{MATERIALS AND METHODS}

\section{Cell line, Medium, and Culture Maintenance}

Murine hybridoma cell line (167.4G5.3) was provided by Dr. Latham Claflin from the Medical Center at The University of Michigan. The antibody produced by this cell line is an $\operatorname{IgG}_{1}$, directed against phosphorylcholine.$^{10}$ Hybridoma cells were made by fusion of $\mathrm{BALB} / \mathrm{c}$ spleen cells with the nonsecreting plasmacytoma fusion line P3X63-Ag8.653. Antibody was generated from mice immunized with PC-keyhole limpet henemocyanin (KLH). The second murine hybridoma cell line (S3H5/ $\gamma 2 \mathrm{bA} 2)$ was provided by Dr. Mark Kaminski from The University of Michigan Medical Center. The antibody produced by this cell line is a $\gamma 2 \mathrm{~b}$ isotype and is specific to the anti-idiotype on the surface of $38 \mathrm{C} 13$ lymphoma cells. ${ }^{11}$ The cells were obtained in the frozen state at an unknown passage number. They were thawed and maintained in $75 \mathrm{~cm}^{2}$ plastic T-flasks (Bellco Glass, Vineland, NJ) using either IMDM (Sigma Chemical, St. Louis, MO) or RPMI-1640 (Sigma). The 167.4G5.3 cells were kept initially in IMDM with $20 \%$ fetal bovine serum (FBS). The $\mathrm{S} 3 \mathrm{H} 5 / \gamma 2 \mathrm{bA} 2$ cells were kept in both IMDM and RPMI-1640 with 5\% FBS. The media were supplemented with 100 units/mL potassium penicillin $\mathrm{G}$ and $100 \mu \mathrm{g} / \mathrm{mL}$ streptomycin sulfate (Sigma). The cells were kept at $37^{\circ} \mathrm{C}$ and $5 \% \mathrm{CO}_{2}$ atmosphere in humidified incubators (VWR Scientific, San Francisco, CA). The cultures were passed every 2 days with a dilution factor of $1: 4$ with fresh media.

\section{Adaptation of Cells to Low Serum}

The 167.4G5.3 cells were adapted to grow at different serum levels for a time period of 6 months. The cells were initially grown in $20 \%$ serum containing IMDM. These cells were frozen and saved for later experiments, and we refer to them as $20 \%$-cells. A portion of these cells was then passed for 2 months in IMDM containing $10 \%$ serum, and the cells so obtained are designated as $10 \%$-cells. A vial of cells was frozen and the rest of the culture was passed for 2 months in IMDM with $5 \%$ serum to give $5 \%$-cells. Similar adaptation led to $2.5 \%$-cells and $1.25 \%$-cells. The $1.25 \%$-cells were also adapted to grow in commercially available serumfree medium. OPTI-MEM (Gibco Laboratories, Grand Island, NY) was used as serum-free medium and OPTIcells were obtained by adaptation of $1.25 \%$-cells in this medium. The cell line $\mathrm{S} 3 \mathrm{H} 5 / \gamma 2 \mathrm{bA} 2$ was originally grown in RPMI and IMDM media with $5 \%$ serum.
These cells were adapted to grow in RPMI and IMDM both containing $1.25 \%$ FBS for about 3 months.

\section{Kinetics of Cell Growth, Metabolism, and Antibody Production}

The cells were propagated in T-flasks until cell viabilities of more than $95 \%$ were reached using IMDM or RPMI-1640 media with the serum concentration to which each cell was adapted. The cells were then inoculated into spinner flasks with different serum concentrations. Thus, the physiological response of each adapted cell to a new serum concentration could be investigated. Exponentially grown cells from T-flasks were centrifuged at $1000 \mathrm{rpm}(200 \mathrm{~g})$ for $10 \mathrm{~min}$. They were then washed with fresh IMDM or RPMI-1640 media containing $1.25 \%$ serum and distributed into spinner flasks containing $50 \mathrm{~mL}$ of IMDM or RPMI-1640 media at different serum concentrations. Four serum concentrations were used: $1.25 \%, 2.5 \%, 5 \%$, and $10 \%$. The spinner flasks were then placed on a stirrer in a humidified $\mathrm{CO}_{2}$ incubator at $37^{\circ} \mathrm{C}$ with $5 \% \mathrm{CO}_{2}$. The agitation rate in the spinner flasks was set at $100 \mathrm{rpm}$. Experiments were run in duplicates.

\section{Analytical Methods}

A 1-mL sample was taken twice daily. After performing cell counts, the samples were centrifuged and the supernatants were stored at $-80^{\circ} \mathrm{C}$ for subsequent determination of metabolite and monoclonal antibody concentrations. Viable and dead cells in suspension were counted using a hemacytometer. Trypan blue exclusion method was used to differentiate dead cells from viable cells.

Glucose and lactate concentrations were measured using a Model 2000 glucose/L-lactate analyzer (Yellow Springs Instruments, Yellow Springs, OH). Ammonia and glutamine were measured with a gas sensing electrode. ${ }^{12}$

Antibodies, $\mathrm{IgG}_{1}$ from $167.4 \mathrm{G} 5.3$ cells and $\mathrm{IgG}_{2 \mathrm{~b}}$ from $\mathrm{S} 3 \mathrm{H} 5 / \gamma 2 \mathrm{bA} 2$ cells were quantified using an enzyme-linked immunosorbent assay (ELISA). Goat antimouse IgG (Sigma) was used to coat wells of plates at a concentration of $10 \mu \mathrm{g} / \mathrm{mL}$ of PBS overnight at $4^{\circ} \mathrm{C}$. The plates were washed with detergent solution (Triton $\mathrm{X} 100$ in PBS), and BSA (1\% in PBS) was applied to the plates for fixation. Aliquots of culture supernatant and purified monoclonal antibodies (MAbs) as standards were then added to the wells [diluted 200 times in $1 \%$ bovine serum albumin (BSA) in PBS]. After 45 min incubation at room temperature, plates were washed and alkaline phosphotase-labeled affinity-purified goat antibody against mouse $\operatorname{IgG}_{1}$ or IgG $_{2 \mathrm{~b}}$ (Southern Biotechnology Associates, Birmingham, AL) was added to the plates. After $45 \mathrm{~min}$, the plates were washed and alkaline phosphotase substrate was added. The optical den- 
sity at $40 \mathrm{Nm}$ or each well was recorded by an ELISA reader (Molecular Devices, Palo Alto, CA).

\section{Flow Cytometry}

A Coulter EPICS 751 flow cytometer was used to measure the antibody content of the cells (Coulter Electronics, Hialeah, FL). Forward angle light scatter (FALS) and $90^{\circ}$ light scatter (90LS) data was used for the estimation of cell size and cell complexity. Viable cells could be differentiated from the dead cells by the differences in their FALS and 90LS characteristics. Dead cells were gated out from the analysis of cellular composition using a software provided by Coulter. Propidium Iodide (PI) was used for the measurement of DNA content of the cells. Stock solutions of propidium iodide were prepared from powder (Sigma) as $1 \mathrm{mg} / \mathrm{mL}$ using phosphate buffer saline (PBS) and stored in 1-mL aliquots at $-80^{\circ} \mathrm{C}$. Cells were treated with RNase (Sigma) to cleave the RNA. Stock solutions of RNase were prepared in PBS as $1 \mathrm{mg} / \mathrm{mL}$ and stored in $1-\mathrm{mL}$ aliquots at $-80^{\circ} \mathrm{C}$. Cells were stained for total intracellular $\operatorname{IgG}_{1}$ or $\operatorname{IgG}_{2 b}$ by Fluorescein isothiocynate conjugated goat antimouse IgG (GAM-FITC from Coulter). The stock concentration of GAM-FITC was $0.02 \mathrm{mg} / \mathrm{mL}$.

Cells were fixed with cold ethanol for analysis of intracellular DNA distribution and IgG content. The cells were fixed as follows: cell samples were spun at $1000 \mathrm{rpm}$ for $5 \mathrm{~min}$ and the cell culture media was removed. Cells were then washed with PBS at pH 7.4 and spun down again for $5 \mathrm{~min}$. The cell pellet was resuspended in $70 \%$ ethanol, and the suspension was kept at $4^{\circ} \mathrm{C}$ overnight. For staining, these fixed cells were spun down at $1000 \mathrm{rpm}$ for $5 \mathrm{~min}$ and washed with PBS. The cells were then centrifuged for $5 \mathrm{~min}$, and the pellet was suspended in $200 \mu \mathrm{L}$ GAM-FITC solution. The cells were incubated for $45 \mathrm{~min}$ at $4^{\circ} \mathrm{C}$. Then the cells were washed with PBS and stained with a mixture of PI and RNase at the concentrations of 20 and $40 \mu \mathrm{g} / \mathrm{mL}$, respectively. This double staining was carried out at $37^{\circ} \mathrm{C}$ for $30 \mathrm{~min}$. The cells were finally washed with PBS and run in the flow cytometer.

\section{Kinetic Analysis of Data}

Experimental data was smoothed by cubic-spline fit to the data, and the rate parameters were evaluated as a function of time. The initial growth rates were calculated in the exponential phase using transient kinetics:

$$
\frac{d X_{T}}{d t}=\mu X_{v}
$$

where $X_{T}$ and $X_{v}$ are the total and viable cells, respectively, $t$ is time, and $\mu$ is the growth rate.

Glucose consumption and lactate production rates were defined with respect to the viable cell counts and were determined using:

$$
-\frac{d[\mathrm{Glu}]}{d t}=q_{\mathrm{Glu}} X_{v}
$$

$$
d[\mathrm{Lac}] d t=p_{\mathrm{Lac}} X_{v}
$$

where $q$ and $p$ are their specific (per cell) consumption and production rates. Ammonia and glutamine kinetics were determined by considering both the first order chemical decomposition of glutamine to ammonia and metabolic activity:

$$
-\frac{d[\mathrm{Gln}]}{d t}=k[\mathrm{Gln}]+q_{\mathrm{Gln}} X_{v}
$$

and

$$
\frac{d\left[\mathrm{NH}_{4}^{+}\right]}{d t}=k[\mathrm{Gln}]+p_{\mathrm{NH}_{4}^{+}} X_{v}
$$

The first order decomposition rate constants of glutamine in IMDM supplemented with different serum concentration have been reported. ${ }^{13}$ Here we use values of $k=0.0023 \mathrm{~h}^{-1}$ for IMDM media and $k=0.0035 \mathrm{~h}^{-1}$ for RPMI-1640 media, which correspond to a $\mathrm{pH}$ value of 7.2, the mean $\mathrm{pH}$ value of cultures in the exponential phase.

The rate parameters calculated from the above models were constant in the exponential phase and decreased later in the stationary and decline phase of the growth. We have described this behavior elsewhere for the kinetic analysis of batch data. ${ }^{13}$ The rates reported here correspond to the exponential phase of the growth.

Monoclonal antibody production rates were calculated using an integral method:

$$
\begin{gathered}
\frac{d M \mathrm{Ab}}{d t}=q_{\mathrm{AB}} X_{\nu}, \quad \text { or } \quad M \mathrm{Ab}=q_{\mathrm{AB}} \int_{0}^{t} X_{\nu} d t \\
\text { if } q_{\mathrm{AB}} \text { is constant }
\end{gathered}
$$

where $M \mathrm{Ab}$ is antibody concentration and $q_{\mathrm{Ab}}$ is the specific production rate, hence obtained from a plot of antibody concentration (MAb) versus time integral of viable cells $\left(\int_{0}^{t} X_{v} d t\right)$. The specific antibody production rate was constant not only in the exponential phase but also in the decline phase of the growth. ${ }^{14}$

\section{RESULTS AND DISCUSSION}

Figure 1 shows the time profiles for concentrations of cell glucose, lactate, glutamine, ammonia, and antibody for $167.4 \mathrm{G} 5.35 \%$-cells and $1.25 \%$-cells. The data for $20 \%$-cells and $10 \%$-cells are not shown, since they are qualitatively similar to that shown for 5\%-cells exhibiting a significant effect of serum concentration. The behavior of $2.5 \%$-cells and OPTI-cells was qualitatively similar to that of $1.25 \%$-cells showing sharply diminished dependence on serum concentration. Figures 2 and 3 show the response of both initial (5\%-) and adapted (1.25\%-) S3H5/ $\gamma 2 \mathrm{bA} 2$ cells to serum in IMDM and RPMI media, respectively. 

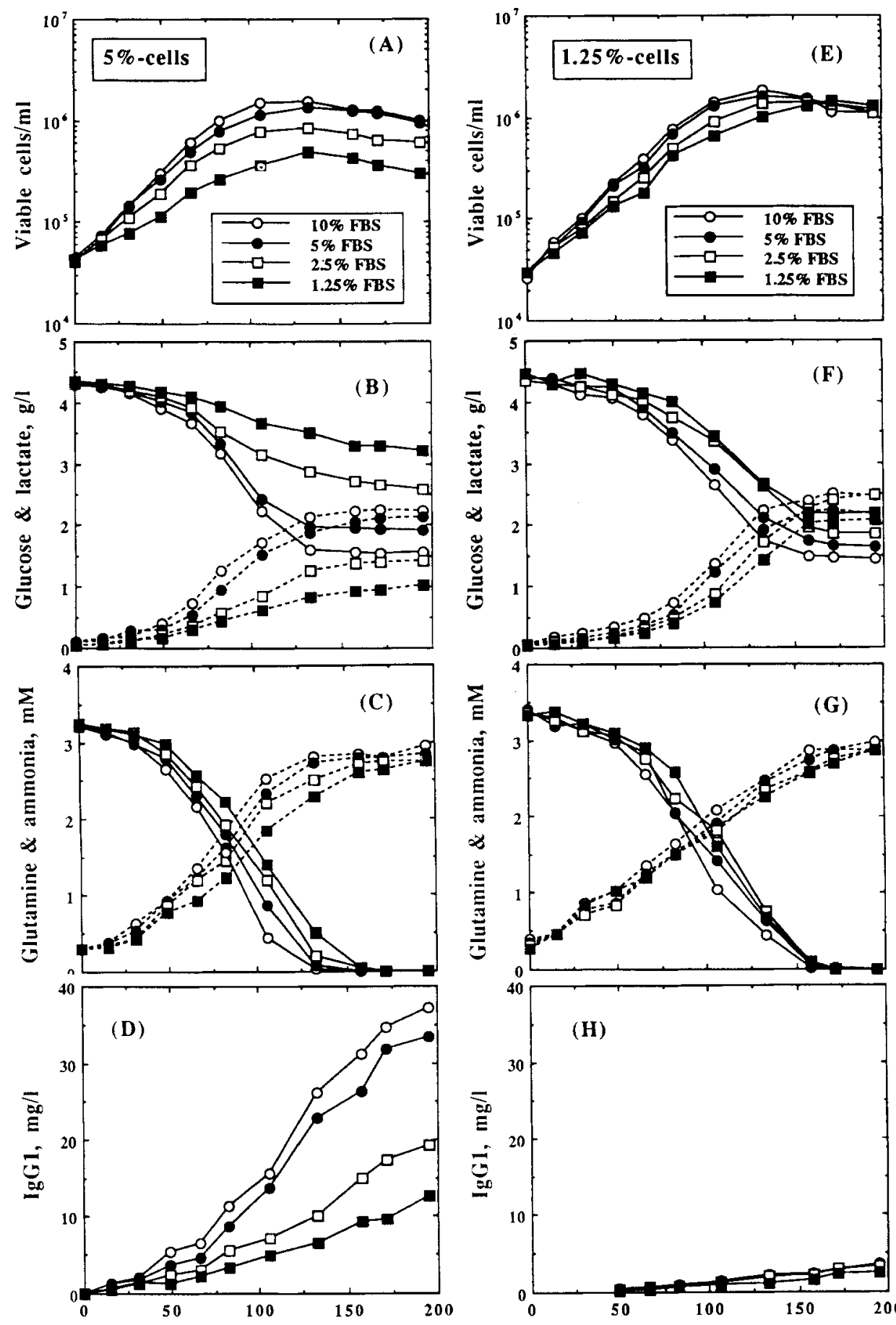

Time, hr

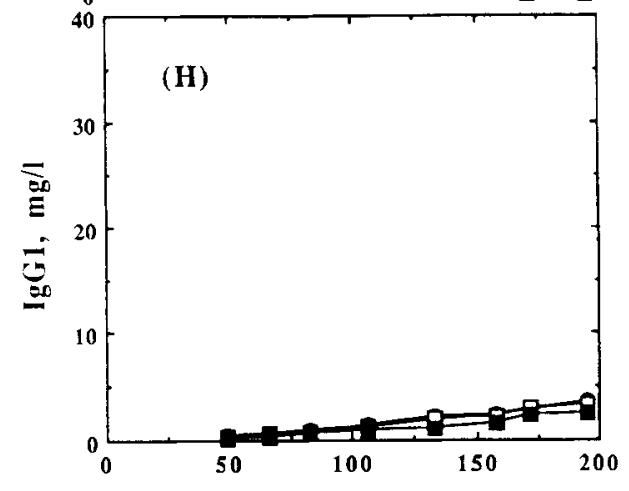

Time, hr

Figure 1. Growth and cell metabolism of hybridoma cell line 167.4G5.3 in IMDM supplemented with different serum concentrations. Left panel is obtained with cells adapted to $5 \%$ serum (5\%-cells) and right panel is obtained with cells adapted to $1.25 \%$ serum (1.25\%-cells). (A) Viable cell concentrations, (B) glucose (solid line) and lactate (dashed line) concentrations, (C) glutamine (solid line) and ammonia (dashed line) concentrations, and (D) IgG $_{1}$ antibody concentration. Legend for serum concentrations used: 10\% FBS (open circle), $5 \%$ (closed circle), $2.5 \%$ (open square), and $1.25 \%$ (closed squares). 

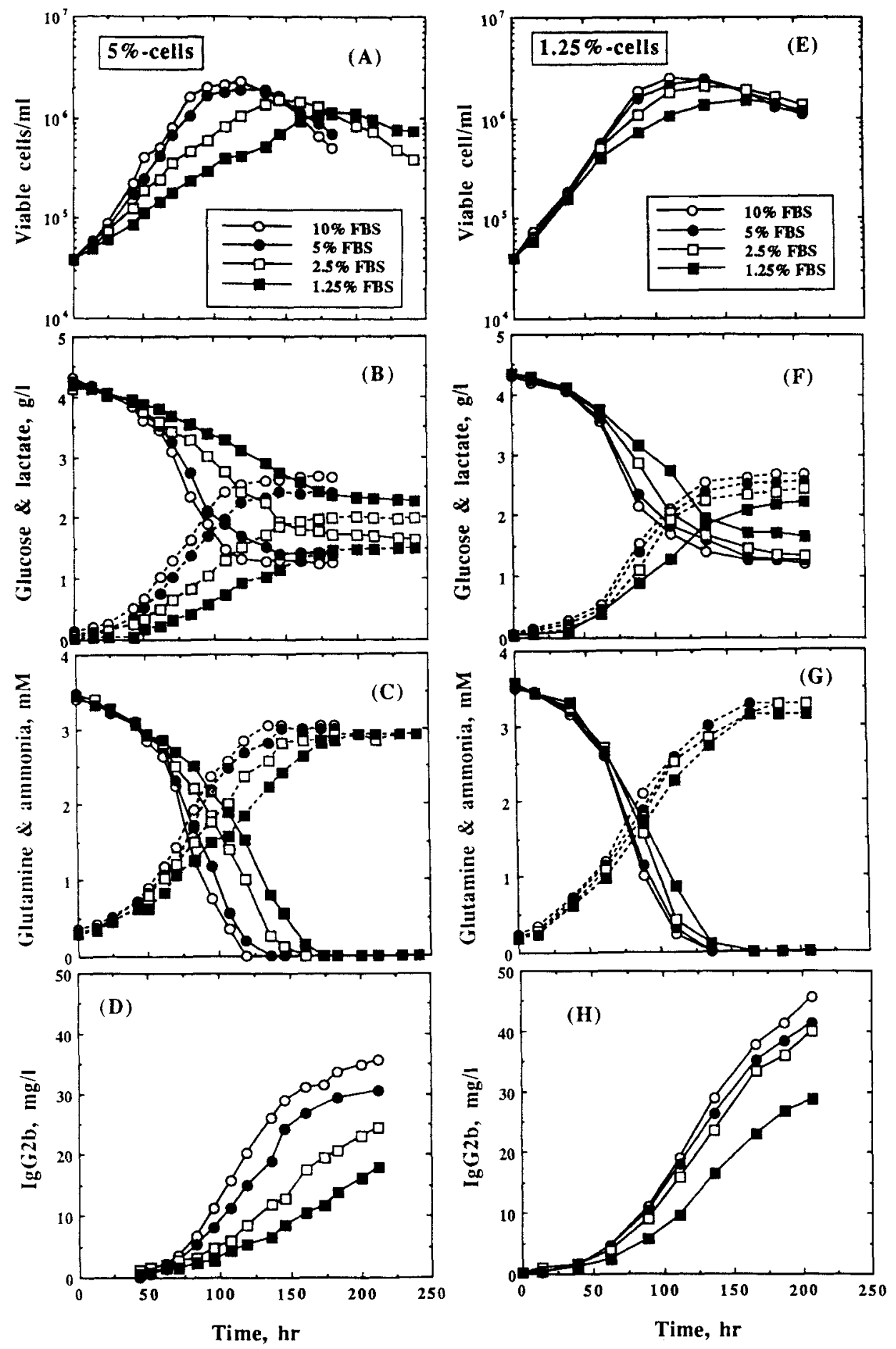

Figure 2. Growth and cell metabolism of hybridoma cell line S3H5/ $/ 2 b A 2$ in IMDM supplemented with different serum concentrations. Left panel is obtained with cells adapted to $5 \%$ serum (5\%-cells) and right panel is obtained with cells adapted to $1.25 \%$ serum (1.25\%-cells). (A) Viable cell concentrations, (B) glucose (solid line) and lactate (dashed line) concentrations, (C) glutamine (solid line) and ammonia (dashed line) concentrations, and (D) $\operatorname{IgG}_{2 \mathrm{~b}}$ antibody concentration. Legend for serum concentrations used: 10\% FBS (open circle), $5 \%$ (closed circle), $2.5 \%$ (open square), and $1.25 \%$ (closed squares). 

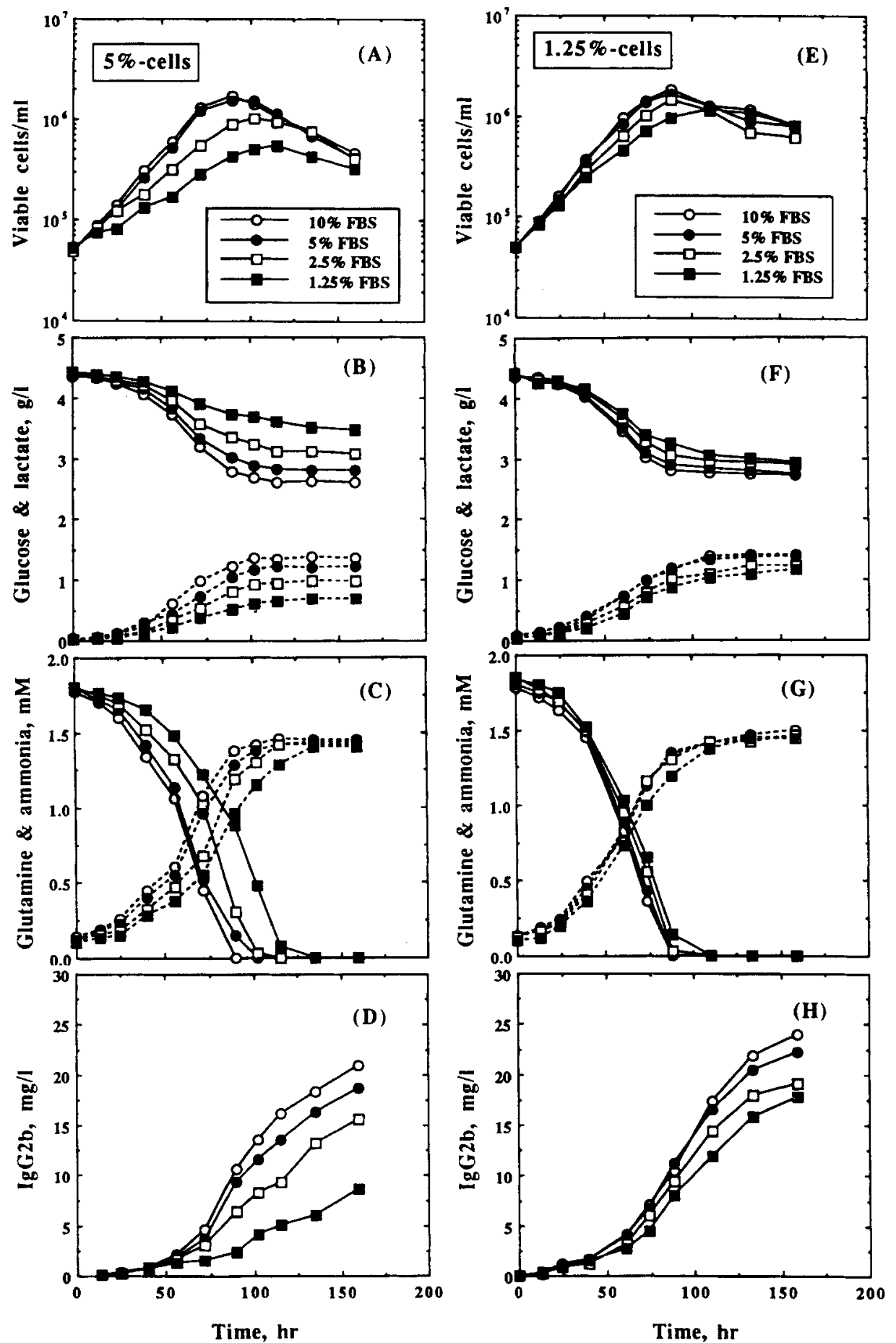

Figure 3. Growth and cell metabolism of hybridoma cell line $\$ 3 H 5 / \gamma 2 b A 2$ in RPMI-1640 media supplemented with different serum concentrations. Left panel is obtained with cells adapted to $5 \%$ serum (5\%-cells) and right panel is obtained with cells adapted to $1.25 \%$ serum (1.25\%-cells). (A) Viable cell concentrations, (B) glucose (solid line) and lactate (dashed line) concentrations, (C) glutamine (solid line) and ammonia (dashed line) concentrations, and (D) $\mathrm{IgG}_{2 \mathrm{~b}}$ antibody concentration. Legend for serum concentrations used: $10 \%$ FBS (open circle), $5 \%$ (closed circle), $2.5 \%$ (open square), and $1.25 \%$ (closed squares). 
For all the adapted cells, the new short-term serum concentration influenced their growth rate. Cells at low serum concentration, i.e., $1.25 \%$ serum, grew slowly as seen from these figures. Cells utilized both glucose and glutamine, and lactate and ammonia were produced. For all the cultures, glutamine was the limiting nutrient and determined the extent of the growth. Glucose, on the other hand, was not depleted and glucose consumption and lactate production ceased following depletion of glutamine. Antibody was produced throughout the culture, both in growth and decline phases.

We will now analyze the experimental data presented in Figures 1-3 to give quantitative information on cell growth and metabolic and antibody production rates as outlined earlier. The rate parameters that we will present are the exponential phase values as indicated in the Materials and Methods section.

\section{Cell Growth}

Cell growth rates were calculated for all the batches, and they are presented in Table I for 167.4G5.3 and in Figure 4 for $\mathrm{S} 3 \mathrm{H} 5 / \gamma 2 \mathrm{bA} 2$ cells. For a given adapted cell, we obtained a higher growth rate at higher serum concentrations. Maximum viable cells obtained in the batch mode were also serum dependent, and higher cell numbers were obtained at higher serum concentrations. These results are in good agreement with earlier reports. ${ }^{13,15,16}$

Cell growth was improved after adaptation to low serum concentration. For a given serum concentration used in batch culture, higher growth rates and higher cell concentrations were obtained for low-serum-adapted cells (Table I). For instance, the growth in $1.25 \%$ serum was only marginal for $20 \%-, 10 \%$, and $5 \%$-serum cells. On the other hand, the 2.5\%-, $1.25 \%$ - and OPTI-cells showed better growth in this serum level as evident from the specific growth rates and the maximum viable cell concentrations (Table I).

Similar growth rate improvement following adaptation was observed for $\mathrm{S} 3 \mathrm{H} 5 / \gamma 2 \mathrm{bA} 2$ cells (Fig. 4). In both IMDM and RPMI media, the growth rates of adapted $\mathrm{S} 3 \mathrm{H} 5 / \gamma 2 \mathrm{bA} 2$ cells were consistently higher than the growth rates of original cells for any given serum concentration. Also, in both media and at all serum concentrations, maximum viable cell concentrations for these adapted cells were consistently higher than those obtained for original cells.

The effect of serum on the growth rate can be expressed mathematically by a Monod-type model which considers serum to be the limiting factor. This type of model has been used by a number of investigators. ${ }^{13,15,16}$ The exponential growth rates reported in Tables I and II were fitted by

$$
\mu=\mu_{\max } \frac{S}{K_{m}+S}
$$

where $\mu$ is the growth rate, $S$ is the serum concentration, $\mu_{\max }$ is the maximum growth rate, and $K_{m}$ is the Monod constant. The parameters that we obtained are summarized in Table II. All growth rates could be described by the above equation with regression coefficients higher than $r^{2}=0.095$.

As seen from Table II, for a given media type and cell line, we obtain relatively constant maximum growth rate $\mu_{\max }$. The maximum growth rate seems to be influenced only by the cell type and the media type. On the other hand, the value of $K_{m}$ decreased consistently as the serum level used for adaptation was lowered. This value may be regarded as a measure of serum requirement, and it is lower for the cells adapted to lower serum concentrations. Thus, the serum requirement of the cells is reduced by adaptation. The value of the $K_{m}$ value also indicates the sensitivity of the growth rate to the serum level. The growth of $20 \%$-cells was strongly dependent on the serum concentration, whereas the $1.25 \%$-cells showed lesser sensitivity to the serum concentration.

\section{Cell Metabolism}

Uptake rates of glucose and glutamine, as well as production rates of lactate and ammonia, were calculated during the exponential phase of growth. Figure 5 shows

Table I. Effect of serum adaptation on cell growth for $167.4 \mathrm{G5} .3$ cells.

\begin{tabular}{|c|c|c|c|c|c|c|}
\hline $\begin{array}{c}\text { FBS } \\
(\% \mathrm{v} / \mathrm{v})\end{array}$ & $20 \%$-cells & $10 \%$-cells & $5 \%$-cells & $2.5 \%$-cells & $1.25 \%$-cells & OPTI-cells \\
\hline \multicolumn{7}{|c|}{ Specific growth rate $\mu, \mathrm{h}^{-1}$} \\
\hline 1.25 & 0.0184 & 0.0182 & 0.0232 & 0.0294 & 0.0322 & 0.0314 \\
\hline 2.5 & 0.0253 & 0.0271 & 0.0296 & 0.0342 & 0.0363 & 0.0372 \\
\hline 5 & 0.0320 & 0.0342 & 0.0352 & 0.0405 & 0.0389 & 0.0394 \\
\hline 10 & 0.0362 & 0.0364 & 0.0384 & 0.0413 & 0.0408 & 0.0412 \\
\hline \multicolumn{7}{|c|}{ Maximum viable cell concentration, $10^{6}$ cells $/ \mathrm{mL}$} \\
\hline 1.25 & 0.28 & 0.32 & 0.45 & 0.96 & 1.02 & 0.98 \\
\hline 2.5 & 0.70 & 0.76 & 0.83 & 1.03 & 1.02 & 1.06 \\
\hline 5 & 0.92 & 0.96 & 1.03 & 1.05 & 1.05 & 1.05 \\
\hline 10 & 1.05 & 1.05 & 1.08 & 1.08 & 1.07 & 1.06 \\
\hline
\end{tabular}

The column headings indicate the adaptation serum levels, while the rows correspond to the short-term serum levels. 

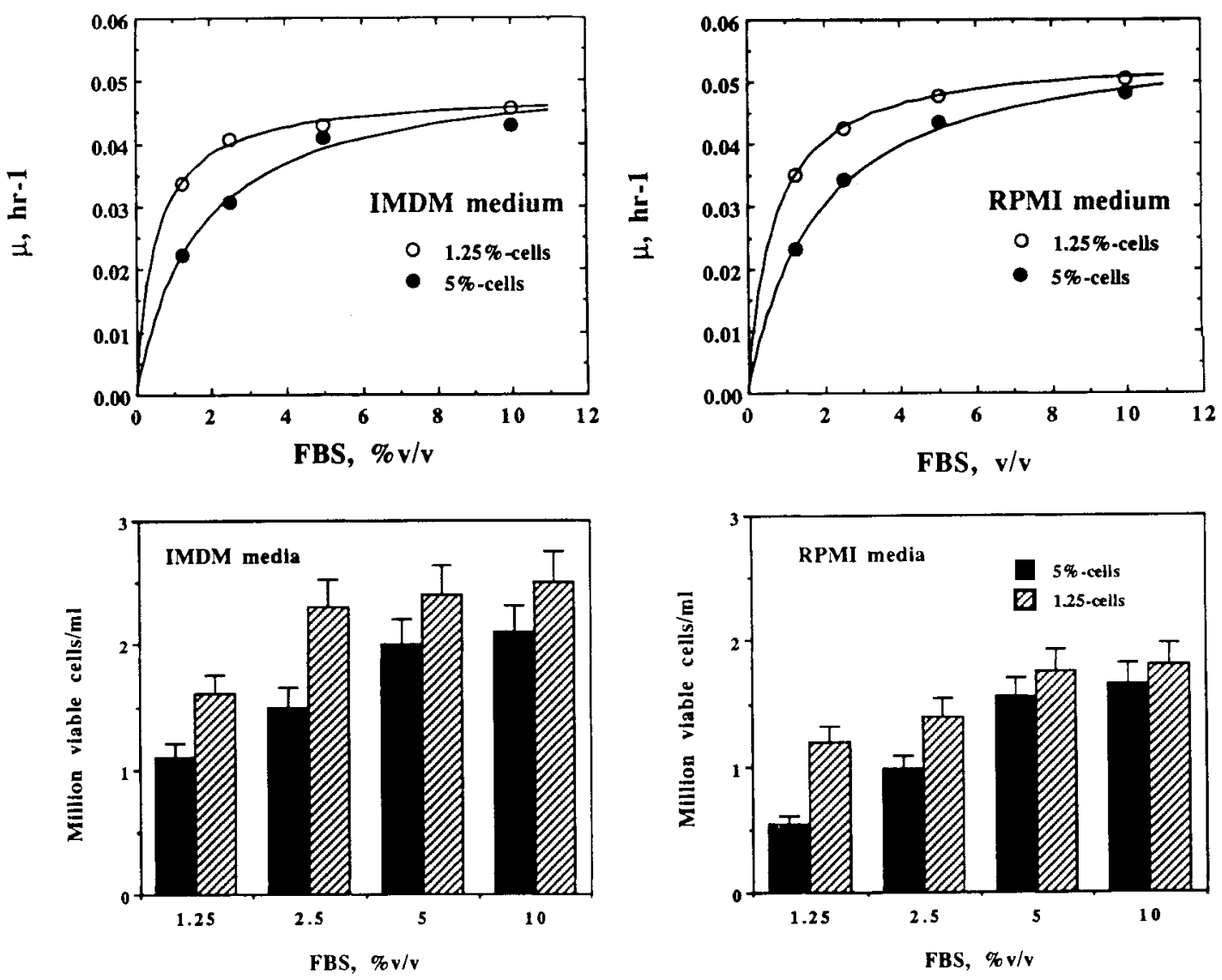

Figure 4. Growth rates (upper panel) and maximum viable cell concentrations (lower panel) for hybridoma cell line $\mathrm{S} 3 \mathrm{H} 5 / \gamma 2 \mathrm{bA} 2$ in different serum concentrations before (5\%-cells) and after $(1.25 \%$-cells) the adaptation to low serum. Data on both IMDM and RPMI-1640 is presented. Solid lines are the predictions of the Monod model with the parameters presented in Table II. The error bars were calculated from data obtained in duplicate flasks.

Table II. Effect of adaptation on Monod parameters.

\begin{tabular}{|c|c|c|c|c|c|}
\hline Cell line & media & $\begin{array}{c}\text { Adaptation } \\
\text { serum, } \% \mathrm{v} / \mathrm{v}\end{array}$ & $\begin{array}{c}\mu_{\max } \\
\mathbf{h}^{-1}\end{array}$ & $\begin{array}{l}K_{m} \\
\% \mathrm{v} / \mathrm{v}\end{array}$ & $r^{2}$ \\
\hline 167.G5.3 & IMDM & 20 & $0.042 \pm 0.04$ & $1.68 \pm 0.07$ & 0.96 \\
\hline $167 . G 5.3$ & IMDM & 10 & $0.045 \pm 0.02$ & $1.78 \pm 0.06$ & 0.97 \\
\hline 167.G5.3 & IMDM & 5 & $0.045 \pm 0.02$ & $1.13 \pm 0.08$ & 0.97 \\
\hline 167.G5.3 & IMDM & 2.5 & $0.044 \pm 0.03$ & $0.67 \pm 0.03$ & 0.97 \\
\hline $167 . G 5.3$ & IMDM & 1.25 & $0.042 \pm 0.04$ & $0.47 \pm 0.05$ & 0.96 \\
\hline 167.G5.3 & OPTI-MEM & 0 & $0.043 \pm 0.02$ & $0.49 \pm 0.03$ & 0.96 \\
\hline $\mathrm{S} 3 \mathrm{H} 5 / \gamma 2 \mathrm{bA} 2$ & IMDM & 5 & $0.050 \pm 0.02$ & $1.52 \pm 0.07$ & 0.98 \\
\hline $\mathrm{S} 3 \mathrm{H} 5 / \gamma 2 \mathrm{bA} 2$ & IMDM & 1.25 & $0.048 \pm 0.01$ & $0.52 \pm 0.03$ & 0.97 \\
\hline $\mathrm{S} 3 \mathrm{H} 5 / \gamma 2 \mathrm{bA} 2$ & RPMI-1640 & 5 & $0.054 \pm 0.02$ & $1.77 \pm 0.08$ & 0.98 \\
\hline $\mathrm{S} 3 \mathrm{H} 5 / \gamma 2 \mathrm{bA} 2$ & RPMI-1640 & 1.25 & $0.053 \pm 0.03$ & $0.69 \pm 0.04$ & 0.99 \\
\hline
\end{tabular}

The growth rates in different serum concentrations were fitted with Monod model and the value of $K_{m}$ and $\mu_{\max }$ were extracted. The error ranges were calculated from duplicate experiments $\left(r^{2}\right.$ is the minimum regression coefficient for the fit).

the metabolic rates for $167.4 \mathrm{G} 5.3$ cells. The kinetic parameters obtained for all the adapted cells are presented as a function of serum concentration. These parameters are insignificantly influenced by the serum level. Glucose and glutamine consumption rates, as well as lactate and ammonia production rates, were relatively constant at values of $0.25 \mu \mathrm{mol} / 10^{6}$ cells $\mathrm{h}$ for glucose, $0.40 \mu \mathrm{mol} / 10^{6}$ cells h for lactate, $0.044 \mu \mathrm{mol} /$ $10^{6}$ cells $\mathrm{h}$ for glutamine, and $0.027 \mu \mathrm{mol} / 10^{6}$ cells $\mathrm{h}$ for ammonia. The yield coefficient of lactate from glucose, $Y_{\mathrm{Lac} / \mathrm{Glu}}$, under these conditions was $1.67 \mathrm{~mol} / \mathrm{mol}$ and the yield coefficient of ammonia from glutamine, $Y_{\mathrm{NH}_{4}+/ \mathrm{Gln}}$, was $0.61 \mathrm{~mol} / \mathrm{mol}$. Similar behavior was also observed for $\mathrm{S} 3 \mathrm{H} 5 / \gamma 2 \mathrm{bA} 2$ cells (Table III). There was 

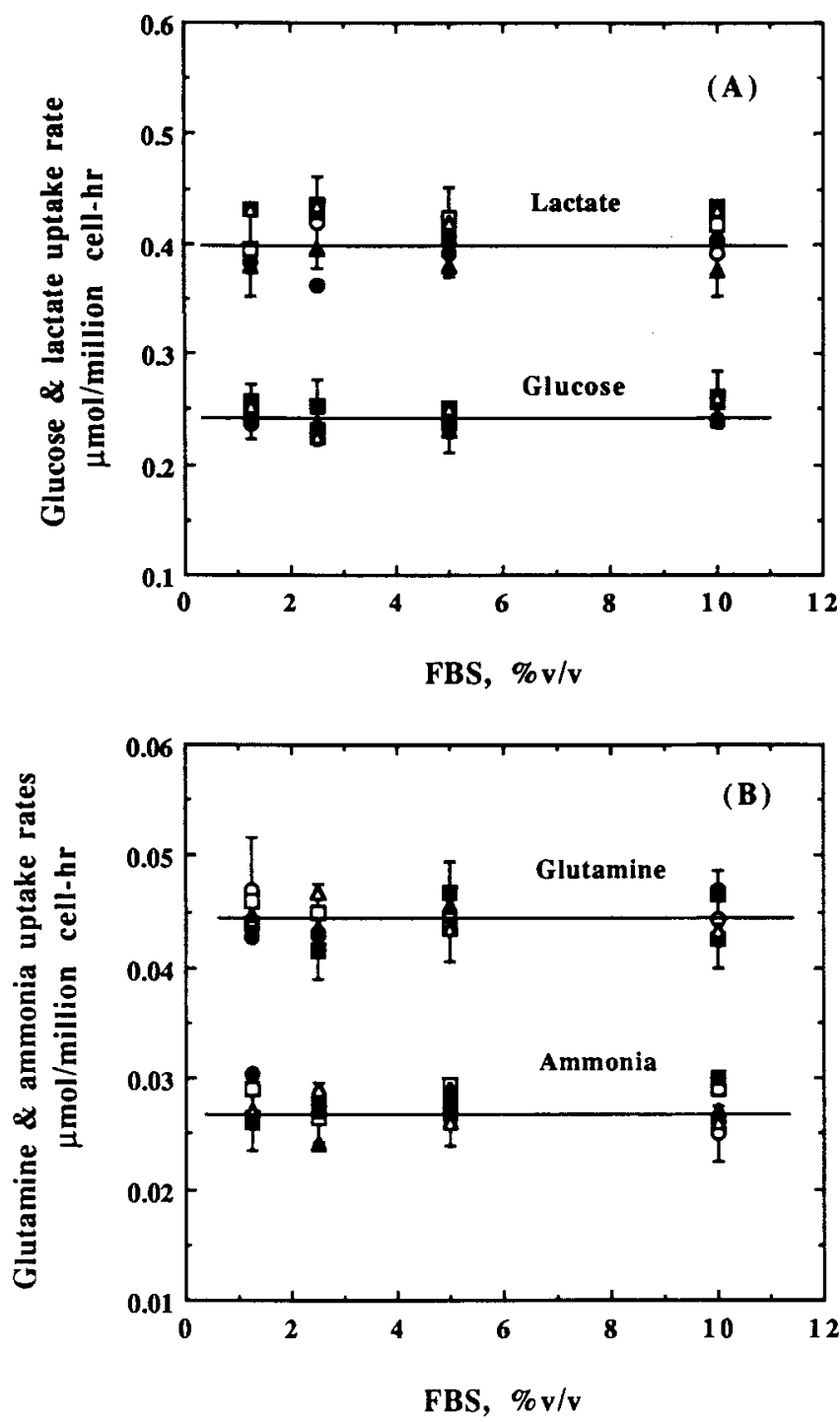

Figure 5. Cell metabolism of hybridoma cell line 167.4G5.3 in IMDM media supplemented with different serum concentrations. (A) Glucose uptake and lactate production rates, (B) glutamine uptake and ammonia production rates. Legend: $20 \%$-cells (open circle), $10 \%$-cells (closed circle), $5 \%$-cells (open square) and $2.5 \%$ cells (closed squares), 1.25\%-cells (open triangle), and OPTI-cells (closed triangle). Error bars were calculated from data obtained in duplicate flasks.

no statistically significant trend in these metabolic rates with changes in the serum concentration.

Comparison of data presented in Figure 5 and Table III reveals that the two cell lines used have slight differences in metabolic rates. When both cells were cultured in IMDM, S3H5/ $\gamma 2 \mathrm{bA} 2$ cells showed about $20 \%$ higher glucose uptake and lactate production rates compared to those of $167.4 \mathrm{G} 5.3$ cells. Glutamine consumption and ammonia production rates were, however, similar: The glucose consumption and lactate production rates for $\mathrm{S} 3 \mathrm{H} 5 / \gamma 2 \mathrm{bA} 2$ cells are lower in RPMI-1640 media as compared to IMDM. Both media had an initial glucose concentration of $4.5 \mathrm{~g} / \mathrm{L}$ (without serum) while glutamine concentration was lower in RPMI-1640 media (IMDM: $4 \mathrm{mM}$, RPMI-1640: $2 \mathrm{mM}$ ).

\section{Antibody Production}

Both short-term serum concentration and adaptation influenced the antibody concentrations obtained (Fig. 1D, 2D, and 3D). The effect of adaptation on antibody production was different for the two cell lines used. As seen from Figure 1D, 167.4G5.3 cells produced less total $\mathrm{IgG}_{1}$ after adaptation to low serum. On the other hand, $\mathrm{S} 3 \mathrm{H} 5 / \gamma 2 \mathrm{bA} 2$ cells resulted in higher antibody concentrations after adaptation due to higher growth rates and cell concentrations.

The antibody concentration obtained from cell line 167.4G5.3 showed an interesting response to adaptation. Antibody concentrations increased during adaptation to 5\% serum but then decreased sharply (Table IV). At any serum concentration, the 5\%-cells produced slightly more antibody compared to $20 \%$ - and $10 \%$-cells due to the higher cell concentrations obtained (Table I). The antibody produced by $5 \%$-cells in $1.25 \%$ serum was about twice the amount produced by $20 \%$-cells in the same medium. The differences in antibody concentration were less pronounced at high serum levels (i.e., $20 \%$ FBS). The 5\%-cells produced more antibody compared to $10 \%$ - and $20 \%$-cells because of their higher growth rates. The specific antibody production rate for $20 \%-, 10 \%$-, and 5\%-cells was essentially the same (Table IV). The $2.5 \%-, 1.25 \%$, and OPTI-cells produced less antibody although the cell concentrations were higher at a given serum concentration, which was due to decrease in the specific antibody production rates (Table IV). These cells lost their specific antibody productivities during adaptation. The loss was the highest in $1.25 \%$-cells, followed by $2.5 \%$-cells and OPTI-cells. This loss of antibody productivity has been studied in detail and the kinetics of loss of antibody productivity during adaptation is described elsewhere. ${ }^{9}$

Cell line $\mathrm{S} 3 \mathrm{H} 5 / \gamma 2 \mathrm{bA} 2$ showed insignificant change in the specific antibody production rate. Figure 6 shows the plot of antibody concentration against time integral of viable cells for the cells grown in IMDM. Both original (5\%-) and adapted (1.25\%-) cells were considered in this figure. The slope of the plot of the antibody concentration versus the integral number of viable cells yields specific antibody productivity as described in Materials and Methods. Both 5\%- and 1.25\%-cells showed similar antibody productivities at all short-term serum concentrations, as all the data points in Figure 6 followed closely the same straight line with $q_{\mathrm{Ab}}=$ $0.175 \pm 0.012 \mathrm{pg} / \mathrm{cell} \mathrm{h}$. The specific antibody productivities of both original and adapted cells in RPMI media were essentially the same $q_{\mathrm{Ab}}=0.173 \pm 0.014 \mathrm{pg} /$ cell $\mathrm{h}$. The amount of antibody produced in IMDM media was higher than in RPMI media in all the cases because of higher cell concentrations (Fig. 7). An unpaired Student $T$-test indicated that the adapted cells $(1.25 \%$-cells) in both media resulted consistently in higher antibody concentrations $(p<0.05)$. This result is important for cost-effective antibody production. 
Table III. Effect of serum adaptation on cell metabolism for cell line S3H5/ $/ 2 \mathrm{bA} 2$.

\begin{tabular}{lcccc}
\hline $\begin{array}{l}\text { FBS, } \\
\% \mathrm{v} / \mathrm{v}\end{array}$ & $\begin{array}{c}\text { Glucose } \\
\text { utilization } \\
q_{\text {Glu }}\end{array}$ & $\begin{array}{c}\text { Lactate } \\
\text { production } \\
p_{\text {Lac }}\end{array}$ & $\begin{array}{c}\text { Glutamine } \\
\text { utilization } \\
q_{\text {Gin }}\end{array}$ & $\begin{array}{c}\text { Ammonia } \\
\text { production } \\
p_{\mathrm{NH}_{4}^{+}}\end{array}$ \\
\hline \multicolumn{5}{c}{ IMDM media } \\
1.25 & $0.344(0.325)$ & $0.527(0.523)$ & $0.044(0.043)$ & $0.027(0.029)$ \\
2.5 & $0.302(0.315)$ & $0.489(0.517)$ & $0.046(0.042)$ & $0.028(0.026)$ \\
5 & $0.299(0.317)$ & $0.502(0.532)$ & $0.042(0.046)$ & $0.027(0.030)$ \\
10 & $0.305(0.293)$ & $0.516(0.492)$ & $0.044(0.044)$ & $0.027(0.027)$ \\
& & RPMI media & & \\
1.25 & $0.270(0.258)$ & $0.386(0.383)$ & $0.040(0.038)$ & $0.027(0.024)$ \\
2.5 & $0.266(0.244)$ & $0.398(0.361)$ & $0.039(0.038)$ & $0.024(0.026)$ \\
5 & $0.259(0.270)$ & $0.386(0.411)$ & $0.037(0.039)$ & $0.023(0.025)$ \\
10 & $0.251(0.247)$ & $0.391(0.385)$ & $0.038(0.039)$ & $0.024(0.025)$ \\
\hline
\end{tabular}

These parameters are presented for 1.25\%-cells (adapted). Numbers in parentheses are the values obtained with the original $5 \%$-cells (before adaptation to $1.25 \%$ ). The metabolic uptake and production rates are in $\mu \mathrm{mol} / 10^{6}$ cell $\mathrm{h}$. The experimental errors in these rates were less than $6 \%$, and there are no statistically significant trend in the rate parameters established by the adaptation process.

Table IV. Effect of adaptation on antibody synthesis for $167.4 \mathrm{G} 5.3$ cells.

\begin{tabular}{|c|c|c|c|c|c|c|}
\hline $\begin{array}{l}\text { FBS, } \\
\% \mathrm{v} / \mathrm{v}\end{array}$ & $20 \%$-cells & $10 \%$-cells & $5 \%$-cells & $2.5 \%$-cells & $1.25 \%$-cells & OPTI-cells \\
\hline \multicolumn{7}{|c|}{$\mathrm{IgG}_{1} \mathrm{mg} / \mathrm{L}$} \\
\hline 1.25 & $7.2 \pm 1.2$ & $8.7 \pm 0.9$ & $13.4 \pm 0.8$ & $6.0 \pm 0.6$ & $2.1 \pm 0.4$ & $4.3 \pm 0.3$ \\
\hline 2.5 & $12.8 \pm 0.5$ & $14.9 \pm 0.7$ & $19.8 \pm 1.1$ & $5.6 \pm 0.4$ & $2.7 \pm 0.3$ & $5.6 \pm 0.2$ \\
\hline 5 & $28.4 \pm 0.9$ & $30.4 \pm 0.9$ & $33 \pm 1.2$ & $6.3 \pm 0.5$ & $2.9 \pm 0.3$ & $6.0 \pm 0.4$ \\
\hline 10 & $32.1 \pm 1.0$ & $35.6 \pm 1.1$ & $37 \pm 1.3$ & $6.4 \pm 0.4$ & $3.5 \pm 0.3$ & $6.2 \pm 0.4$ \\
\hline \multicolumn{7}{|c|}{$q_{\mathrm{Ab}}, \mathrm{pg} /$ cell h } \\
\hline 1.25 & $0.196 \pm 0.012$ & $0.198 \pm 0.015$ & $0.202 \pm 0.016$ & $0.076 \pm 0.005$ & $0.020 \pm 0.004$ & $0.082 \pm 0.003$ \\
\hline 2.5 & $0.202 \pm 0.015$ & $0.218 \pm 0.017$ & $0.187 \pm 0.020$ & $0.080 \pm 0.008$ & $0.023 \pm 0.003$ & $0.085 \pm 0.006$ \\
\hline 5 & $0.194 \pm 0.013$ & $0.208 \pm 0.021$ & $0.217 \pm 0.011$ & $0.092 \pm 0.007$ & $0.020 \pm 0.003$ & $0.091 \pm 0.005$ \\
\hline 10 & $0.196 \pm 0.011$ & $0.198 \pm 0.014$ & $0.195 \pm 0.012$ & $0.091 \pm 0.008$ & $0.019 \pm 0.002$ & $0.078 \pm 0.008$ \\
\hline
\end{tabular}

The experimental errors were calculated from duplicate experiments.

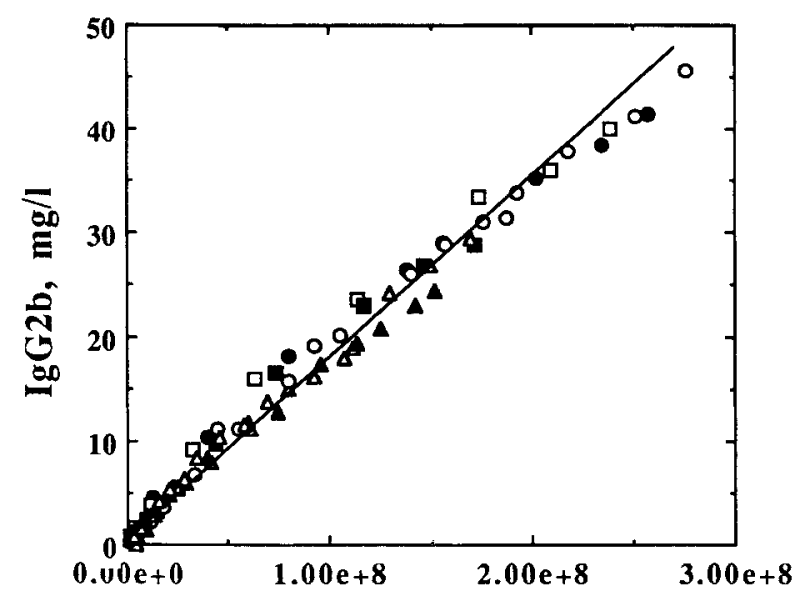

Integral of viable cells

Figure 6. Antibody production kinetics of $\$ 3 \mathrm{H} 5 / \gamma 2 \mathrm{bA} 2$ cells. Antibody concentrations were plotted against time integral of viable cells $\left(\int_{0}^{t} X_{v} d t\right)$. The slope of the line gives a specific antibody production rate of $q_{\mathrm{Ab}}=0.175 \pm 0.012 \mathrm{pg} / \mathrm{cell} \mathrm{h}$. Different symbols represent data obtained in IMDM with different serum concentrations. Both $5 \%$-cells (closed symbols) and $1.25 \%$-cells (open symbols) were considered in the figure. The specific antibody production rate was not influenced significantly by adaptation and by serum for this cell line.
Adaptation to low-serum media results in both higher cell concentrations and higher antibody titers. As seen from Figure 7, the titer obtained with adapted cells in $1.25 \%$ serum is comparable to the titer obtained in $10 \%$ serum with nonadapted $5 \%$-cells.

The loss of antibody productivity in 167.4G5.3 cells can be explained by flow cytometric analysis. Figure 8 shows the intracellular antibody concentrations for both $5 \%$ - and $1.25 \%$-cells. The 5\%-cells that did not lose the antibody productivity had a single population with respect to intracellular antibody content. On the other hand, the $1.25 \%$-cells consisted of two populations. One population had similar intracellular antibody content to that of 5\%-cells while the other population had one order of magnitude lower antibody content. The 2.5\%- and OPTI-cells also showed two population histograms. Frame et al. ${ }^{17}$ and Heath et al. ${ }^{18}$ also reported similar internal antibody distributions. The kinetics of the loss of antibody productivity has been studied in detail, ${ }^{9}$ and the loss in antibody productivity in these cultures could then be attributed to the presence of the low antibody-containing cells.

The $\mathrm{S} 3 \mathrm{H} 5 / \gamma 2 \mathrm{bA} 2$ cells did not lose their antibody productivity over the same time period of adaptation. 

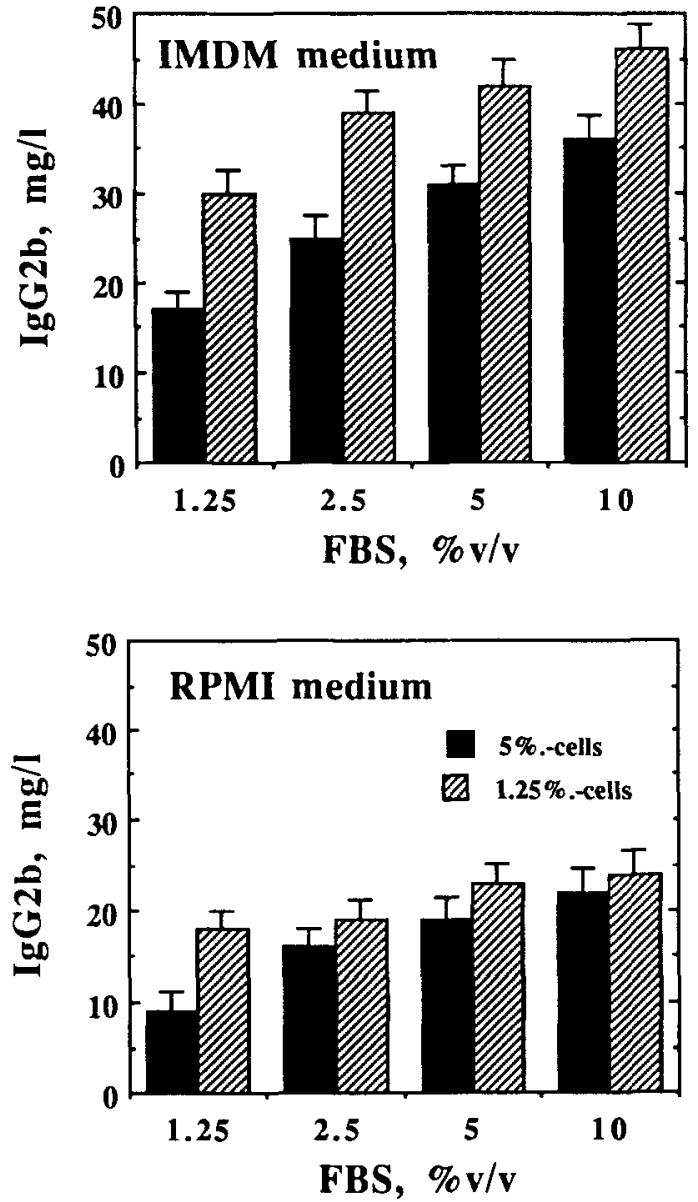

Figure 7. The influence of adaptation on antibody production in different serum concentrations for $\mathrm{S} 3 \mathrm{H} 5 / \gamma 2 \mathrm{bA} 2$ cells. Adapted cells resulted in consistently higher antibody concentrations. Error bars were calculated from data obtained in duplicate flasks.

The intracellular antibody content of these cells showed single populations for both original and adapted cells.

\section{Effect of Adaptation on Intracellular Composition}

Adaptation also did not influence intracellular composition of the cells. Cell size, protein and RNA content, and DNA distribution for both cell lines were not altered by adaptation. In Figure 9 we present the size and DNA distribution of $\mathrm{S} 3 \mathrm{H} 5 / \gamma 2 \mathrm{bA} 2$ cells. The distributions were similar for both original (5\%-) and adapted $(1.25 \%-)$ cells. Further, the adaptation in both IMDM and RPMI media did not change the protein and RNA content of the cells (data not shown). We have reported elsewhere that there are no significant differences among the adapted 167.4G5.3 cells in terms of cell size, protein and RNA content, and DNA distribution. ${ }^{9}$ Hence it seems that the preservation of physical properties and intracellular composition is common between the two cell lines used, although $167.4 \mathrm{G} 5.3$ cells showed a difference in that they lost their antibody productivity.

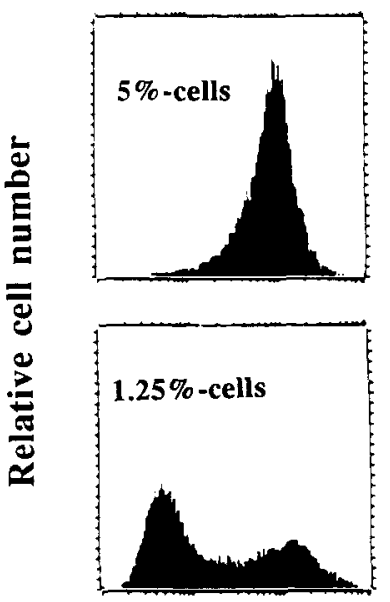

\section{Log Green fluorescence (IgG)}

Figure 8. Variations in the intracellular antibody content of the hybridoma cells during adaptation. Both 167.4G5.3 and $\mathrm{S} 3 \mathrm{H} 5 / \gamma 2 \mathrm{bA} 2$ cells were adapted from $5 \%$ serum to $1.25 \%$ serum in the same time period and the intracellular antibody concentrations were measured in a flow cytometer. Green fluorescence correlates the antibody content of the cells. Cell line 167.4G5.3 showed a drop in antibody produciton and exhibited two population whereas cell line $\mathrm{S} 3 \mathrm{H} 5 / \gamma 2 \mathrm{bA} 2$ preserved the productivity and the presence of a single population.

\section{CONCLUSIONS}

We have adapted two cell lines to grow at different serum concentrations. Experiments were carried out in two different media (IMDM and RPMI-1640). Changes in growth rate, cell metabolic, and antibody production rate were determined.

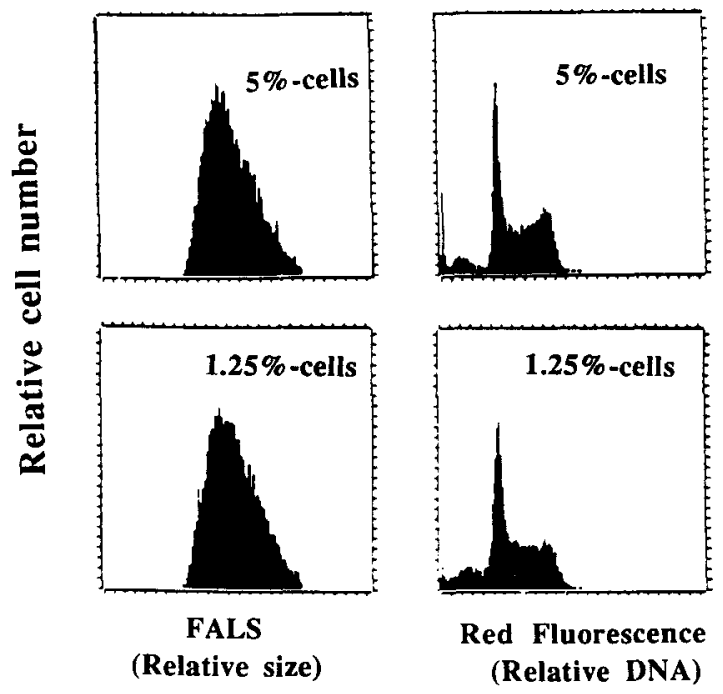

Figure 9. Cell size and DNA distribution for $\mathrm{S} 3 \mathrm{H} 5 / \gamma 2 \mathrm{bA} 2$ cells before (5\%-cells) and after $(1.25 \%$-cells) the adaptation to low serum. Cells growing in IMDM with 5\% FBS were analyzed in a flow cytometer. Both cell size and DNA distribution were not influenced by adaptation. 
For any given adapted cells, we observed that the concentration of serum used influenced the growth rates. The increase in cell growth at high serum concentrations is most likely due to the higher concentrations of serum growth stimulatory factors. However, metabolic uptake rates and yield coefficients were not influenced, and therefore, the cells produce the same amount of metabolic energy. This energy is used for both growth and maintenance. At high serum concentrations, it seems that cells are using the metabolic resources efficiently for growth, while the fraction used for growth decreases at low serum concentrations. The weaker coupling of cellular resources to growth is presumably due to lower concentrations of growth factors.

For a given short-term serum concentration, we observed that the cells adapted to low serum levels grew better. This increase in the growth rate was due to the lower serum requirement following adaptation as depicted by the $K_{m}$ values (Table III). Both cell lines lost their sensitivity to external growth factors after longterm exposure to low serum levels. This loss could be due to (1) increased ability of production of cell-derived growth factors and (2) the decrease of the cell's serum requirements for growth factors after adaptation, possibly because of changes in receptor concentrations in the cell membrane. Briand and Lykkesfeldt ${ }^{8}$ have observed the latter phenomenon for a cancer cell line. More work is needed for testing these hypotheses for hybridoma cells.

We have observed that specific antibody production rate is not affected by the short-term serum concentration, and the lower antibody concentrations obtained at low-serum or serum-free media were due to lesser cell growth. Growth improvement by adaptation can be utilized to obtain higher antibody concentrations under identical conditions. We have observed this for $\mathrm{S} 3 \mathrm{H} 5 /$ $\gamma 2 \mathrm{bA} 2$ cells. However, the loss of antibody productivity, as illustrated by $167.4 \mathrm{G} 5.3$ cells, emphasizes an important limitation to such improvements. Long-term exposure to low-serum or to serum-free media can result in loss of specific antibody productivity.
Flow cytometric data showed that cellular gross macromolecular composition was not altered by adaptation. The adapted cells did not show any physical differences under the microscope and the cell size was about the same. Along with the metabolic data presented above, these measurements suggest that insignificant physical or metabolic changes take place during adaptation.

This work was supported by National Science Foundation Grant No. EET-8712756. The authors thank Drs. J. Latham Claflin and Mark Kaminski for providing the hybridoma cell lines used in this study and Mark Cameron for his help in acquiring the flow cytometric data.

\section{References}

1. H. Murakami, in Monoclonal Antibodies: Production and Application, A. Mizrahi, Ed. (Alan R. Liss, New York, 1989), p. 108.

2. H. R. Maurer, in Animal Cell Culture: A Practical Approach, R. I. Freshney, Ed. (IRL Press, Oxford, 1986), p. 13.

3. S. D. Wolpe, in Mammalian Cell Culture, J. P. Mather, Ed. (Premium, New York, 1984), p. 103.

4. J. Kovar and F. Franek, Meth. Enz., 121, 227 (1986)

5. B. Griffiths, Devel. Biol. Stand., 66, 155 (1987).

6. I. Kovar, In Vitro Cell. Devel. Biol., 25, 395 (1989).

7. B. L. Brown, in Commercial Production of Monoclonal Antibodies: A Guide for Scale-up, S.S. Seaver, Ed. (Marcel Dekker, New York, 1987) p. 35.

8. P. Briand and A. E. Lykkesfeldt, Canc. Res., 44, 1114 (1984),

9. S. S. Ozturk and B. O. Palsson, Hybridoma, 9, 167, (1990).

10. D. E. Briles, C. Forman, S. Hudak, and J. L. Claflin, Eur. J. Immunol., 14, 1027 (1984).

11. M.S. Kaminski, K. Kitamura, D. G. Maloney, and R. Levy, J. Immunol., 138, 1289 (1987).

12. S. S. Ozturk, M. E. Meyerhoff, and B. O. Palsson, Biotechnol. Techn. 3, 217 (1989).

13. S.S. Ozturk and B. O. Palsson Biotechnol. Prog., 6, 121 (1990).

14. S. S. Ozturk and B. O. Palsson, J. Biotechnol., (to appear).

15. M.W. Glacken, E. Adema, and A. J. Sinskey, Biotechnol. Bioeng., 32, 491 (1988).

16. M. Dalili and D. Ollis, Biotechnol. Bioeng., 33, 984 (1989).

17. K. Frame, S. Sen, and W.-S., Hu, Biotechnol. Bioeng., 35, 469 (1990).

18. C. A. Heath, R. Dilwith, and G. Belfort, J. Biotechnol. (to appear). 